\title{
Proprioception and neuromuscular control after the modified Broström procedure at the timing of a return to sports: A retrospective study
}

Jin Hyuck Lee

Korea University College of Medicine and School of Medicine

Hae Woon Jung

Kyung Hee University Medical Center

Woo Young Jang ( $\square$ opmanse@gmail.com )

Korea University Anam Hospital https://orcid.org/0000-0003-1775-7715

Research article

Keywords: Proprioception; Neuromuscular control; Modified Broström procedure; Postural

Posted Date: March 13th, 2020

DOI: https://doi.org/10.21203/rs.3.rs-17193/v1

License: (c) (i) This work is licensed under a Creative Commons Attribution 4.0 International License. Read Full License 


\section{Abstract}

Background: The modified Broström procedure (MBP) is an initial treatment in symptomatic chronic ankle instability (CAI) patients. However, there was a deficiency of studies regarding the recovery of proprioception and neuromuscular control at the timing of a return to sports after MBP. This study aimed to compare the proprioception and neuromuscular control of both affected and unaffected ankles at the timing of a return to sports after MBP in CAI patients with those of normal controls. Methods: Totally, 75 patients (40 who underwent MBP vs. 35 normal controls) participated. Proprioception and neuromuscular control were measured by postural stability and time to peak torque, respectively. Postural stability tests included static and dynamic balance and the star excursion balance test (SEBT). Static and dynamic balance were tested using a postural stabilometry system, and time to peak torque was measured using an isokinetic device. Results: The dynamic balance test was significantly higher in the affected ankle of the MBP group than in controls $(1.5 \pm 0.6$ vs. $1.1 \pm 0.4, p<0.003)$. SEBT was significantly lower in the affected ankle of the MBP group compared to controls (anterior: 70.9 \pm 16.4 vs. $80.3 \pm 11.7, p<0.006$; posterior: 49.2 \pm 10.0 vs. $62.2 \pm 19.0$, $p<0.000$; lateral: $49.9 \pm 12.7$ vs. $57.3 \pm 17.7, p<0.040$ ). Time to peak torque was significantly increased in the affected ankle of the MBP group compared to controls (dorsiflexion: $608.3 \pm$ 139.4 vs.522.9 $\pm 175.8, p<0.022$; eversion: $689.1 \pm 191.6$ vs. $593.1 \pm 211.2, p<0.043$ ). Conclusion: Dynamic balance, SEBT, and time to peak torque in CAI patients remained significantly reduced at the timing of a return to sports after MBP. Keywords : Proprioception; Neuromuscular control; Modified Broström procedure; Postural stability; Star excursion balance test

\section{Background}

The main causes of chronic ankle instability (CAI) are mechanical joint instability, peroneal muscle weakness, and lack of proprioception and neuromuscular control [1, 2]. In particular, deficits of lateral ankle ligaments, including the anterior talofibular ligament (ATFL) and calcaneofibular ligament (CFL), can lead to mechanical joint instability, which may accelerate CAI [3]. For these reasons, many authors have advocated that surgical treatment is required in $10-30 \%$ of patients who experience unsuccessful conservative treatment $[2,4,5]$. Therefore, the modified Broström procedure (MBP) is typically used as the initial treatment in symptomatic CAI patients [6].

Many studies have reported that insufficient proprioception and neuromuscular control may be the primary cause of ankle instability [6-9] and may also increase the risk of re-injury $[1,10,11]$. In particular, postural control [12-14] and peroneal muscle reaction time $[13,15,16]$ may be significant factors in the outcomes of CAI. While some authors reported good results using the MBP in most patients [17], many patients still experience subjective instability and persistent pain due to proprioception and neuromuscular control deficits after surgical treatment [18-20]. However, the recovery of proprioception and neuromuscular control after MBP for CAI has rarely been investigated. Furthermore, although the recommended timeframe for a return to non-contact sports after ligament surgery has generally been 3 months after surgery [21-24], no studies have investigated proprioception and neuromuscular control at 3 months after MBP. Therefore, the purpose of this study was to compare the proprioception and neuromuscular control of both affected 
and unaffected ankles at 3 months after MBP in CAI patients with those of normal controls. We hypothesized that the proprioception and neuromuscular control at 3 months after MBP would be recovered as normal controls.

\section{Methods}

\section{Participants}

Ethics approval was provided by the institutional review board of our institute. Informed consent was obtained from all individual participants included in the study. A total of 73 patients who underwent MBP among 168 patients with CAI were identified from 2013 to 2017 in this retrospective case-control study. All patients had undergone plain radiographic testing on both ankles to identify lateral ankle ligament injuries. Mechanical ankle instability was assessed by presence of a talar tilt of more than $9^{\circ}$ or a difference between both ankles of more than $3^{\circ}$ or $3 \mathrm{~mm}$ in anterior drawer [25]. Any disagreements regarding physical examinations and all images were resolved by consensus of two experienced surgeons. All patients with CAI underwent conservative treatment from 1 to 3 months. If they had constant symptomatic ankle instability and persistent pain with failure of conservative treatment, MBP was recommended. All patients who underwent MBP showed ATFL tear with or without CFL tear on performing magnetic resonance imaging and instability on stress plain radiographs. Thirty-three patients were excluded for the following reasons (Fig. 1): injury to both ankles, medial ankle ligament injury, revised ankle surgery, refusal to be examined due to persistent pain after surgery, neuromuscular disease, acute ankle sprain, and osteochondral lesions. Then, 40 patients were allocated to the MBP group (12.4 weeks after MBP on average), and 35 normal control subjects were selected from our database of volunteers with no history of ankle joint injury. Finally, 75 participants ( 40 who underwent MBP vs. 35 normal controls) were enrolled.

\section{Evaluation tests}

Recent studies have reported that patients who underwent MBP returned to sports at 12 weeks $[24,26]$ and that proprioception and neuromuscular control are critical factors for a successful return to sports $[14,27]$. However, the terminology for proprioception and neuromuscular control in those studies was often used interchangeably $[14,27]$. In the present study, proprioception and neuromuscular control tests were separately evaluated by postural stability and time to peak torque tests, respectively.

Since proprioception plays an important role in balance control [28], the postural stability test was performed using the Biodex Stability System (BBS; Biodex Medical Systems). While the static balance test involves the patient maintaining their posture on level 12 (most stable) of the platform, the dynamic balance test involves maintaining their posture as the stability gradually decreases from level 12 (most stable) to level one (most unstable), with the level automatically declining every $1.66 \mathrm{sec}$. The BSS provides a $20^{\circ}$ tilt and $360^{\circ}$ rotation of the platform. For this test, all participants stood barefoot with one leg on the platform while the opposite leg was held in the flexed position off the platform, with their hands at the back of their pelvis. Each test was performed for 2 trials, with rest time of $10 \mathrm{sec}$ between each leg. If the participant was unable to maintain posture, that test was canceled. Each test was performed for $20 \mathrm{sec}$ 
to record postural stability parameters including the overall stability index (OSI), with a lower stability index indicating good postural stability $[25,29]$.

A systematic review reported that the star excursion balance test (SEBT) reliably assesses dynamic postural stability and functional performance in lower extremity injuries such as ankle instability and anterior cruciate ligament rupture [30]. In the present study, the SEBT was performed in a similar manner to the dynamic postural stability test, with calculation of the average reach distance from the 3 trials in the anterior, posterior, and lateral directions, while standing on each foot [30]. Measurements from the 3 trials were normalized to the leg length of each patient, which was measured from the anterior superior iliac spine to the distal portion of the medial malleolus of the ankle in the supine position [30, 31]. A greater reach distance indicates good postural stability and proprioception.

The neuromuscular control test was performed using a quantified isokinetic device (Biodex Multi-Joint System 4, Biodex Medical Systems Inc., Shirley, NY). Neuromuscular control can be defined as the coordination or co-contraction of muscles for joint stability [32]. Neuromuscular control was measured using the time to peak torque, which reflects muscular recruitment time and was defined as the arrival time from the initial contraction to the peak torque during muscle contraction [33]. Time to peak torque was recorded during 15 muscle contractions at $120 \% \mathrm{sec}$, with a rest time of $30 \mathrm{sec}$ between each foot and a rest time of 1 min between each test, in eversion and dorsiflexion.

\section{Postoperative rehabilitation protocol}

Postoperative rehabilitation was divided into 3 phases in our clinic. All patients had cast immobilization for 2 weeks after MBP. The initial phase started at 2 to 4 weeks postoperatively and included range of motion (ROM) and isometric muscle strengthening exercises with gradual full weight bearing. From 6 weeks postoperatively, the second phase introduced concentric and eccentric muscle strengthening of the hip, knee, and ankle joints and balance exercises to improve proprioception. From 10 weeks postoperatively, the third phase involved incremental muscle strengthening and plyometric exercises, including dynamic balance exercises, to improve neuromuscular control. Running and a return to noncontact sports were allowed at 12 weeks. All participants performed the rehabilitation protocol for both ankles 1 or 2 times per week for 12 weeks after surgery and were instructed as to the home rehabilitation program.

\section{Statistical analysis}

Based on a previous study for postural stability in patients with ankle instability [25, 34], an OSI difference $>0.5$ between the groups was considered to represent a clinical difference. A power analysis was performed to determine the sample size, with an alpha level of 0.05 and a power of 0.8 . The results of a pilot study involving 5 ankles in each group indicated that 54 ankles were required to detect significant differences in the OSI of $>0.5$ between the groups. The power necessary to detect such differences in OSI was 0.810 .

All continuous variables are described as 'mean \pm SD.' The Student's t-test was used to compare proprioception (postural stability) and neuromuscular control (time to peak torque) in both affected and unaffected ankles between the MBP and normal control groups. The Shapiro test was used to determine 
whether a continuous variable followed a normal distribution. The statistical level of significance was set at $p$ value $<0.05$. Statistical analysis was performed using IBM SPSS Statistics software (ver. 21.0; Chicago, Illinois).

\section{Results}

Table 1 presents demographic data. There were no significant differences in age, height, or weight between the MBP and normal control groups.

Table 1

Demographic data of subjects in the modified Broström procedure and normal control groups

\begin{tabular}{|c|c|c|c|}
\hline & $\begin{array}{l}\text { Modified Broström procedure } \\
\text { group } \\
(n=40)\end{array}$ & $\begin{array}{l}\text { Normal control group } \\
(n=35)\end{array}$ & $P$ value \\
\hline Sex (male/female) & $25 / 15$ & $21 / 14$ & \\
\hline Age (years) ${ }^{a}$ & $27.3 \pm 3.6$ & $24.8 \pm 2.2$ & .542 \\
\hline Height $(\mathrm{cm})^{a}$ & $176.1 \pm 0.8$ & $175.3 \pm 0.4$ & .794 \\
\hline Weight $(\mathrm{kg})^{a}$ & $61.3 \pm 4.4$ & $63.2 \pm 6.5$ & .626 \\
\hline Body mass index $\left(\mathrm{kg} / \mathrm{m}^{2}\right)^{\mathrm{a}}$ & $22.1 \pm 2.4$ & $23.2 \pm 3.6$ & .512 \\
\hline Injured side (right/left) & $28 / 12$ & $21 / 14$ & \\
\hline $\begin{array}{l}\text { Sports and activity level, } \mathrm{n} \\
\text { (low:high) }^{\text {a }}\end{array}$ & $15: 25$ & $12: 23$ & .412 \\
\hline
\end{tabular}

Preoperative dynamic balance test in the affected ankles were significantly improved after MBP $(1.8 \pm 1.1$ vs. $1.5 \pm 0.6, p=0.002)$, but was not in the static balance test $(p>0.05$, Fig. 2$)$. The static balance test showed no significant difference in both the affected and unaffected ankles between the groups $(p>0.05$, Table 2). The dynamic balance test was significantly higher in the affected ankle of the MBP group than in that of the normal control group ( $1.5 \pm 0.6$ vs. $1.1 \pm 0.4, p<0.003)$, with no difference in the unaffected ankle ( $p>0.05$, Table 2). Preoperative SEBT in the affected ankles was significantly improved after MBP (anterior: $59.4 \pm 14.9$ vs. $70.9 \pm 16.4, p=0.004$; posterior: $40.2 \pm 9.1$ vs. $49.2 \pm 10, p=0.036$; lateral: $39 \pm 13.1$ vs. $49.9 \pm 12.7, p=0.003)$, but was not in the unaffected ankles ( $p>0.05$, Fig. 2). SEBT in the anterior, posterior, and lateral directions was significantly lower in the affected ankle of the MBP group than in that of the normal control group (anterior: $70.9 \pm 16.4$ vs. $80.3 \pm 11.7, p<0.006$; posterior: $49.2 \pm 10.0$ vs. $62.2 \pm$ 19.0, $p<0.000$; lateral: $49.9 \pm 12.7$ vs. $57.3 \pm 17.7, p<0.040$; Table 2), with no difference in the unaffected ankle $(p>0.05$ (Table 2$)$. 
Table 2

Postural stability between the modified Broström procedure and normal control groups

\begin{tabular}{|c|c|c|c|c|c|c|}
\hline & \multicolumn{3}{|l|}{ Unaffected ankle } & \multicolumn{3}{|l|}{ Affected ankle } \\
\hline & $\begin{array}{l}\text { Modified Broström } \\
\text { procedure group }\end{array}$ & $\begin{array}{l}\text { Normal } \\
\text { control } \\
\text { group }\end{array}$ & $\begin{array}{l}\mathrm{P} \\
\text { value }\end{array}$ & $\begin{array}{l}\text { Modified } \\
\text { Broström } \\
\text { procedure group }\end{array}$ & $\begin{array}{l}\text { Normal } \\
\text { control group }\end{array}$ & $\begin{array}{l}\mathrm{P} \\
\text { value }\end{array}$ \\
\hline $\begin{array}{l}\text { Static } \\
\text { balance, } \\
\text { Mean } \pm \text { SD }\end{array}$ & $1.1 \pm 0.4$ & $\begin{array}{l}1.0 \pm \\
0.4\end{array}$ & .806 & $1.2 \pm 0.4$ & $1.1 \pm 0.4$ & .245 \\
\hline MD, (95\% Cl) & $0.1,(-0.2,0.2)$ & & & $0.1,(-0.1,0.3)$ & & \\
\hline $\begin{array}{l}\text { Dynamic } \\
\text { balance, } \\
\text { Mean } \pm \text { SD }\end{array}$ & $1.3 \pm 0.6$ & $\begin{array}{l}1.1 \pm \\
0.3\end{array}$ & .088 & $1.5 \pm 0.6$ & $1.1 \pm 0.4$ & $\begin{array}{l}.003 \\
\mathrm{a}\end{array}$ \\
\hline $\mathrm{MD}, 95 \% \mathrm{Cl}$ & $0.2,(0,0.4)$ & & & $0.4,(0.1,0.6)$ & & \\
\hline $\begin{array}{l}\text { SEBT } \\
\text { anterior, } \\
\text { Mean } \pm \text { SD }\end{array}$ & $83.7 \pm 9.2$ & $\begin{array}{l}84.3 \\
\pm \\
12.6\end{array}$ & .818 & $70.9 \pm 16.4$ & $\begin{array}{l}80.3 \pm \\
11.7\end{array}$ & $\begin{array}{l}.006 \\
\mathrm{a}\end{array}$ \\
\hline MD, $(95 \% \mathrm{Cl})$ & $-0.4,(-5.6,4.4)$ & & & $-9.4,(-16.0,-2.7)$ & & \\
\hline $\begin{array}{l}\text { SEBT } \\
\text { posterior, } \\
\text { Mean } \pm \text { SD }\end{array}$ & $56.7 \pm 12.0$ & $\begin{array}{l}61.9 \\
\pm \\
13.2\end{array}$ & .079 & $49.2 \pm 10.0$ & $\begin{array}{l}62.2 \pm \\
19.0\end{array}$ & $\begin{array}{l}.000 \\
\mathrm{a}\end{array}$ \\
\hline $\mathrm{MD}, 95 \% \mathrm{Cl}$ & $-5.2,(-10.9,0.6)$ & & & $-13,(-19.9,6.1)$ & & \\
\hline $\begin{array}{l}\text { SEBT lateral, } \\
\text { Mean } \pm \text { SD }\end{array}$ & $56.4 \pm 17.2$ & $\begin{array}{l}59.1 \\
\pm \\
16.2\end{array}$ & .486 & $49.9 \pm 12.7$ & $\begin{array}{l}57.3 \pm \\
17.7\end{array}$ & $\begin{array}{l}.040 \\
a\end{array}$ \\
\hline MD, (95\% Cl) & $-2.7,(-10.4,5.0)$ & & & $-7.4,(-14.4,-0.3)$ & & \\
\hline \multicolumn{7}{|c|}{ astatistically significant } \\
\hline
\end{tabular}

Preoperative time to peak torque for dorsiflexion and eversion in the affected ankles was significantly improved after MBP (dorsiflexion: $688.7 \pm 150.7$ vs. $608.3 \pm 139.4, p=0.035$; eversion: $761.9 \pm 184.1$ vs. $689.1 \pm 191.6, p=0.047)$, but was not in the unaffected ankles ( $p>0.05$, Fig. 2$)$. Time to peak torque for dorsiflexion and eversion was significantly increased in the affected ankle of the MBP group compared with that of the normal control group (dorsiflexion: $608.3 \pm 139.4$ vs. $522.9 \pm 175.8, p<0.022$; eversion: $689.1 \pm 191.6$ vs. $593.1 \pm 211.2, p<0.043)$ (Table 3$)$, with no difference in the unaffected ankle $(p>0.05$, Table 3). 
Table 3

Time to peak torque between the modified Broström procedure and normal control groups

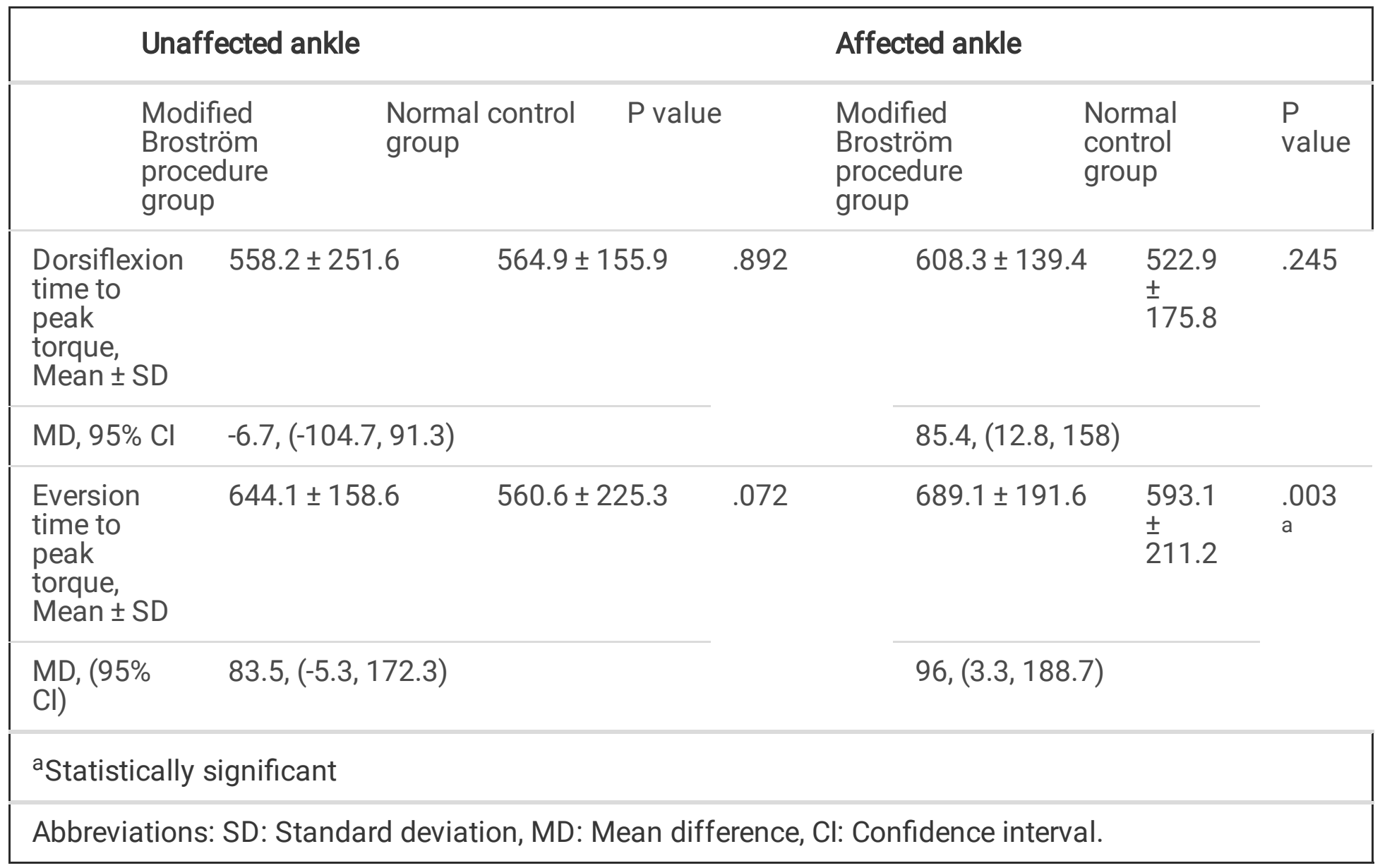

\section{Discussion}

The most important result of the present study was that static balance in the affected ankles did not significantly differ between the MBP and normal control groups. However, dynamic balance, SEBT, and time to peak torque were significantly reduced in the affected ankles of the MBP group compared with those of the normal control group.

In the postural stability tests, static postural stability showed no significant differences in both the affected and unaffected ankles between groups, though dynamic postural stability, including dynamic balance and SEBT, was significantly reduced in the affected ankles of the MBP group compared with those of the normal controls. Although the reason for this result is unclear, it can likely be explained by mechanoreceptors. Mechanoreceptors are sensory receptors located in the ligaments that provide sensory information from external stimuli [35], and they include Pacinian corpuscles (rapidly adapting mechanoreceptors) and Ruffini endings and Golgi tendon organs (slow-adapting mechanoreceptors) [36]. Recent studies have reported that compared with Ruffini endings and Golgi tendon organs, Pacinian corpuscles predominate in the lateral ligaments of the human ankle [35,37], which make them especially capable of detecting motion and dynamic sense. Therefore, loss of mechanoreceptors can affect dynamic postural stability in the dynamic balance test and SEBT $[35,37]$, but it does not necessarily affect static 
postural stability. Another possible reason for this result may be the insufficient recovery of ligaments. A previous study found that deficits of the lateral ankle ligament may decrease postural stability due to increased mechanical instability [7]. In a study by Li et al [12], postural stability was significantly improved at 6 months after MBP. However, in the present study, the postural stability test was performed at 3 months after MBP. Hubbard et al reported that improvements in mechanical stability did not occur within 3 months of injury [38]. Therefore, these findings indicate that dynamic postural stability tests such as dynamic balance and SEBT are important factors in the assessment of improvements in mechanical stability in CAI patients who underwent MBP.

In the present study, time to peak torque for dorsiflexion and eversion was significantly increased in the affected ankles of the MBP group compared with those of normal control groups. One possible explanation of the difference in results between the MBP and normal control groups is that muscular recruitment time may not be affected by surgical repair. As previously mentioned, rapidly adapting mechanoreceptors are prevalent in the lateral ankle ligament compared with slow-adapting mechanoreceptors. MBP is performed to facilitate improvement in mechanical stability, but muscular recruitment time is detected by muscle mechanoreceptors, which are slow-adapting mechanoreceptors. Furthermore, Johnson and Johnson reported that the latency time of the peroneal muscles did not recover on performing electromyography (EMG) after surgical repair [15]. Similarly, Li et al reported that the reaction times of dorsiflexion and eversion did not improve on performing EMG after MBP [12], and Konradsen et al demonstrated that delayed muscle reaction time was not related to ligament injury or mechanical instability [39]. Given that the results of the present study were consistent with those of previous studies, we believe that proprioception and neuromuscular training should be considered as a method to improve muscular recruitment time in dorsiflexion and eversion $[40,41]$.

This study had several limitations. First, there is the possibility that visual compensation may directly affect postural stability, as reported by Li et al [12]. However, the control screen was covered to reduce any bias in the postural stability tests in the present study. Second, we did not perform EMG in the assessment of neuromuscular response. However, isokinetic devices are valid indirect measurement tools for the assessment of muscular response, including muscular reaction time, by measuring the time to peak torque $[33,42]$. Despite these limitations, to the best of our knowledge, this is the first study to determine the differences in proprioception and neuromuscular control between CAI patients who underwent MBP and normal controls.

\section{Conclusions}

Dynamic balance, SEBT, and time to peak torque in CAI patients remained significantly reduced at the timing of a return to sports after MBP. Therefore, clinicians and therapists should be aware of these potential deficits in proprioception and neuromuscular control when determining the timing of a return to sports after MBP in CAI patients.

\section{List Of Abbreviations}


Modified Broström procedure (MBP); Chronic ankle instability (CAI); Star excursion balance test (SEBT); Anterior talofibular ligament (ATFL); Calcaneofibular ligament (CFL); Biodex Stability System (BBS); Range of motion (ROM); Overall stability index (OSI); Electromyography (EMG)

\section{Declarations}

\section{Ethics approval and consent to participate:}

The study protocol was approved by Korea University Anam Hospital Institutional Review Board (ED17143). Because of the study's retrospective design, the need for consent to participate was waived.

Consent for publication: Not applicable

Availability of data and materials: The datasets used and/or analyzed during the current study are available from the corresponding author on reasonable request.

\section{Competing interests}

The authors declare that they have no competing interests.

\section{Funding:}

This research was supported by the NRF grant funded by the Korea government (NRF 2018R1C1B6005202)

\section{Authors' contributions:}

JHL and WYJ collected and analyzed the patient clinical data. JHL and HWJ and WYJ interpreted data and were major contributors to writing the manuscript. All authors read and approved the final manuscript.

\section{Acknowledgements:}

Not applicable

\section{References}

1. Hertel J. Functional Anatomy, Pathomechanics, and Pathophysiology of Lateral Ankle Instability. J Athl Train. 2002;37:364-75.

2. Karlsson J, Bergsten T, Lansinger O, Peterson L. Reconstruction of the lateral ligaments of the ankle for chronic lateral instability. J Bone Joint Surg Am. 1988;70:581-8.

3. Kobayashi T, Gamada K. Lateral Ankle Sprain and Chronic Ankle Instability: A Critical Review. Foot Ankle Spec. 2014;7:298-326.

4. Karlsson J, Eriksson BI, Bergsten T, Rudholm O, Sward L. Comparison of two anatomic reconstructions for chronic lateral instability of the ankle joint. Am J Sports Med. 1997;25:48-53. 
5. Konradsen L, Bech L, Ehrenbjerg M, Nickelsen T. Seven years follow-up after ankle inversion trauma. Scand J Med Sci Sports. 2002;12:129-35.

6. Michels F, Pereira H, Calder J, Matricali G, Glazebrook M, Guillo S, et al. Searching for consensus in the approach to patients with chronic lateral ankle instability: ask the expert. Knee Surg Sports Traumatol Arthrosc. 2018;26:2095-102.

7. Chen H, Li HY, Zhang J, Hua YH, Chen SY. Difference in postural control between patients with functional and mechanical ankle instability. Foot Ankle Int. 2014;35:1068-74.

8. Hirai D, Docherty CL, Schrader J. Severity of functional and mechanical ankle instability in an active population. Foot Ankle Int. 2009;30:1071-7.

9. Rivera MJ, Winkelmann ZK, Powden CJ, Games KE. Proprioceptive Training for the Prevention of Ankle Sprains: An Evidence-Based Review. J Athl Train. 2017;52:1065-7.

10. Gross MT. Effects of recurrent lateral ankle sprains on active and passive judgements of joint position. Phys Ther. 1987;67:1505-9.

11. Refshauge KM, Kilbreath SL, Raymond J. The effect of recurrent ankle inversion sprain and taping on proprioception at the ankle. Med Sci Sports Exerc. 2000;32:10-5.

12. Li HY, Zheng JJ, Zhang J, Cai YH, Hua YH, Chen SY. The improvement of postural control in patients with mechanical ankle instability after lateral ankle ligaments reconstruction. Knee Surg Sports Traumatol Arthrosc. 2016;24:1081-5.

13. Sierra-Guzman R, Jimenez F, Abian-Vicen J. Predictors of chronic ankle instability: Analysis of peroneal reaction time, dynamic balance and isokinetic strength. Clin Biomech (Bristol, Avon). 2018;54:28-33.

14. McKeon PO, Hertel J. Systematic review of postural control and lateral ankle instability, part I: can deficits be detected with instrumented testing. J Athl Train. 2008;43:293-304.

15. Johnson MB, Johnson CL. Electromyographic response of peroneal muscles in surgical and nonsurgical injured ankles during sudden inversion. J Orthop Sports Phys Ther. 1993;18:497-501.

16. Levin O, Vanwanseele B, Thijsen JR, Helsen WF, Staes FF, Duysens J. Proactive and reactive neuromuscular control in subjects with chronic ankle instability: evidence from a pilot study on landing. Gait Posture. 2015;41:106-11.

17. McCriskin BJ, Cameron KL, Orr JD, Waterman BR. Management and prevention of acute and chronic lateral ankle instability in athletic patient populations. World J Orthop. 2015;6:161-71.

18. Lynch SA, Renstrom PA. Treatment of acute lateral ankle ligament rupture in the athlete. Conservative versus surgical treatment. Sports Med. 1999;27:61-71.

19. Kibler WB. Arthroscopic findings in ankle ligament reconstruction. Clin Sports Med. 1996;15:799-804.

20. Maffulli N, Del Buono A, Maffulli GD, Oliva F, Testa V, Capasso G, et al. Isolated anterior talofibular ligament Brostrom repair for chronic lateral ankle instability: 9-year follow-up. Am J Sports Med. 2013;41:858-64.

21. Jones AP, Sidhom S, Sefton G. A minimally invasive surgical technique for augmented reconstruction of the lateral ankle ligaments with woven polyester tape. J Foot Ankle Surg. 2007;46:416-23. 
22. Paterson R, Cohen B, Taylor D, Bourne A, Black J. Reconstruction of the lateral ligaments of the ankle using semi-tendinosis graft. Foot Ankle Int. 2000;21:413-9.

23. White WJ, McCollum GA, Calder JD. Return to sport following acute lateral ligament repair of the ankle in professional athletes. Knee Surg Sports Traumatol Arthrosc. 2016;24:1124-9.

24. Yoo JS, Yang EA. Clinical results of an arthroscopic modified Brostrom operation with and without an internal brace. J Orthop Traumatol. 2016;17:353-60.

25. Lee JH, Lee SH, Choi GW, Jung HW, Jang WY. Individuals with recurrent ankle sprain demonstrate postural instability and neuromuscular control deficits in unaffected side. Knee Surg Sports Traumatol Arthrosc. 2018; doi:10.1007/s00167-018-5190-1.

26. Matsui K, Takao M, Miyamoto W, Matsushita T. Early recovery after arthroscopic repair compared to open repair of the anterior talofibular ligament for lateral instability of the ankle. Arch Orthop Trauma Surg. 2016;136:93-100.

27. Zech A, Hubscher M, Vogt L, Banzer W, Hansel F, Pfeifer K. Balance training for neuromuscular control and performance enhancement: a systematic review. J Athl Train. 2010;45:392-403.

28. Pasma JH, Boonstra TA, Campfens SF, Schouten AC, Van der Kooij H. Sensory reweighting of proprioceptive information of the left and right leg during human balance control. J Neurophysiol. 2012;108:1138-48.

29. Lee JH, Heo JW, Lee DH. Comparative postural stability in patients with lateral meniscus versus medial meniscus tears. Knee. 2018;25:256-61.

30. Gribble PA, Hertel J, Plisky P. Using the Star Excursion Balance Test to assess dynamic postural-control deficits and outcomes in lower extremity injury: a literature and systematic review. J Athl Train. 2012;47:339-57.

31. Gribble PA, Hertel J. Considerations for Normalizing Measures of the Star Excursion Balance Test. Measurement in Physical Education and Exercise Science. 2003;7:89-100.

32. Riemann BL, Lephart SM. The Sensorimotor System, Part II: The Role of Proprioception in Motor Control and Functional Joint Stability. J Athl Train. 2002;37:80-4.

33. Lee JH, Park JS, Hwang HJ, Jeong WK. Time to peak torque and acceleration time are altered in male patients following traumatic shoulder instability. J Shoulder Elbow Surg. 2018;27:1505-11.

34. Lee JH, Lee SH, Jung HW, Jang WY. Modified Brostrom procedure in patients with chronic ankle instability is superior to conservative treatment in terms of muscle endurance and postural stability. Knee Surg Sports Traumatol Arthrosc. 2020;28:93-9.

35. Wu X, Song W, Zheng C, Zhou S, Bai S. Morphological study of mechanoreceptors in collateral ligaments of the ankle joint. J Orthop Surg Res. 2015;10:92.

36. Michelson JD, Hutchins C. Mechanoreceptors in human ankle ligaments. J Bone Joint Surg Br. 1995;77:219-24.

37. Moraes MR, Cavalcante ML, Leite JA, Ferreira FV, Castro AJ, Santana MG. Histomorphometric evaluation of mechanoreceptors and free nerve endings in human lateral ankle ligaments. Foot Ankle Int. 2008;29:87-90. 
38. Hubbard TJ, Hicks-Little CA. Ankle ligament healing after an acute ankle sprain: an evidence-based approach. J Athl Train. 2008;43:523-9.

39. Konradsen L, Beynnon B, Renstrom P. Proprioception and sensorimotor control in the functionally unstable ankle. Proprioception and neuromuscular control in joint stability. Champaign, IL: Human Kinetics. 2000:237-46.

40. Osborne MD, Chou LS, Laskowski ER, Smith J, Kaufman KR. The effect of ankle disk training on muscle reaction time in subjects with a history of ankle sprain. Am J Sports Med. 2001;29:627-32.

41. Pozzi F, Moffat M, Gutierrez G. NEUROMUSCULAR CONTROL DURING PERFORMANCE OF A DYNAMIC BALANCE TASK IN SUBJECTS WITH AND WITHOUT ANKLE INSTABILITY. Int J Sports Phys Ther. 2015;10:520-9.

42. Mattiello-Rosa SM, Camargo PR, Santos AA, Padua M, Reiff RB, Salvini TF. Abnormal isokinetic timeto-peak torque of the medial rotators of the shoulder in subjects with impingement syndrome. $J$ Shoulder Elbow Surg. 2008;17:54s-60s.

\section{Figures}


Chronic ankle instability patients $(\mathrm{n}=168)$

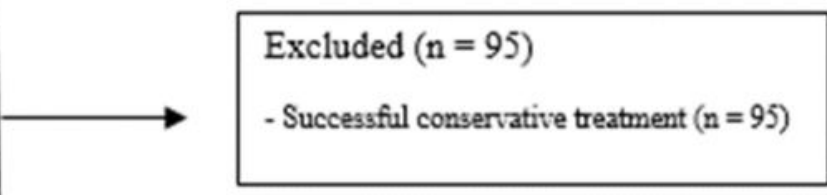

Chronic ankle instability patients who underwent the modified Broström procedure $(n=73)$

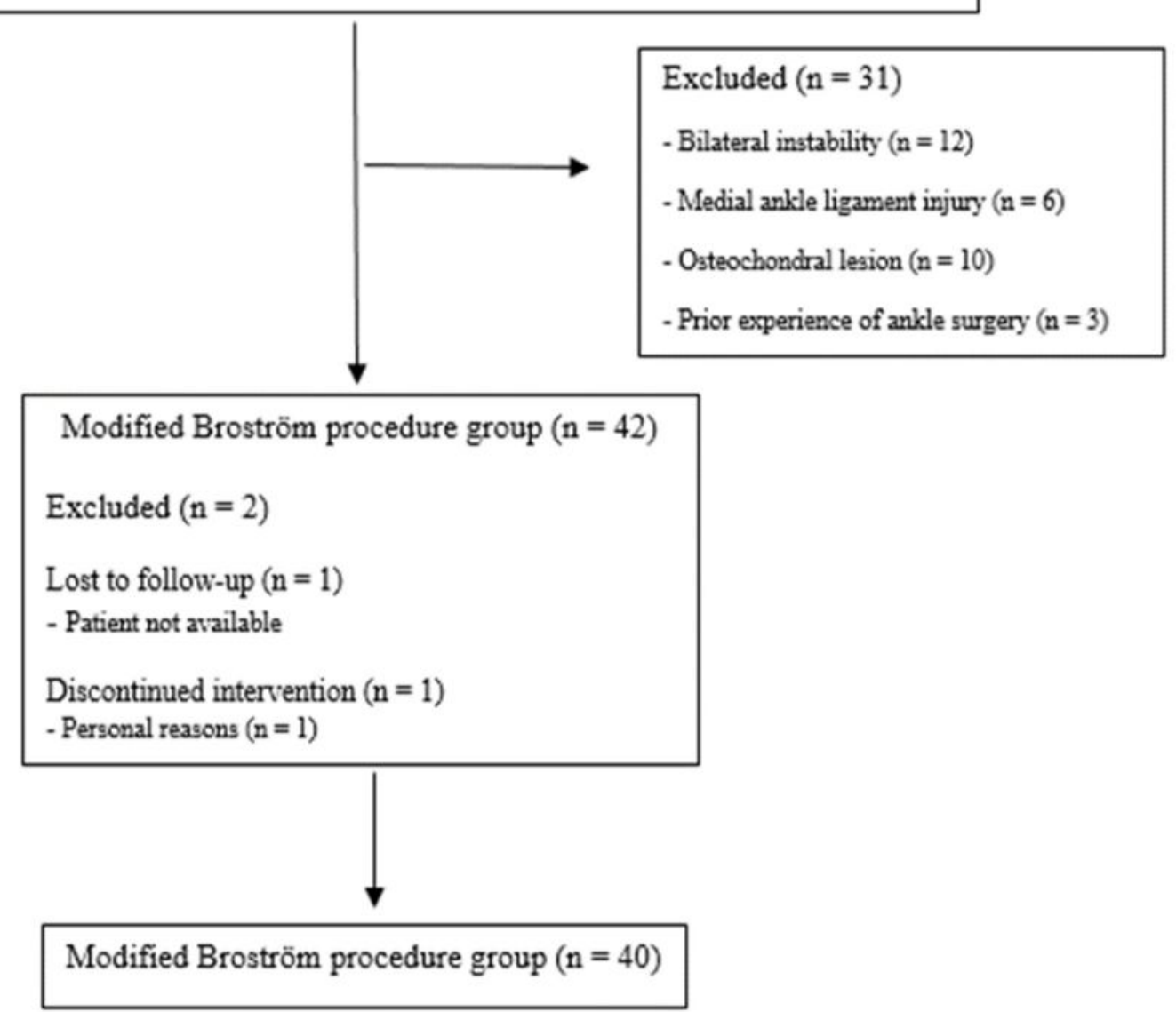

Figure 1

Flowchart of CAI patients who underwent the modified Broström procedure 

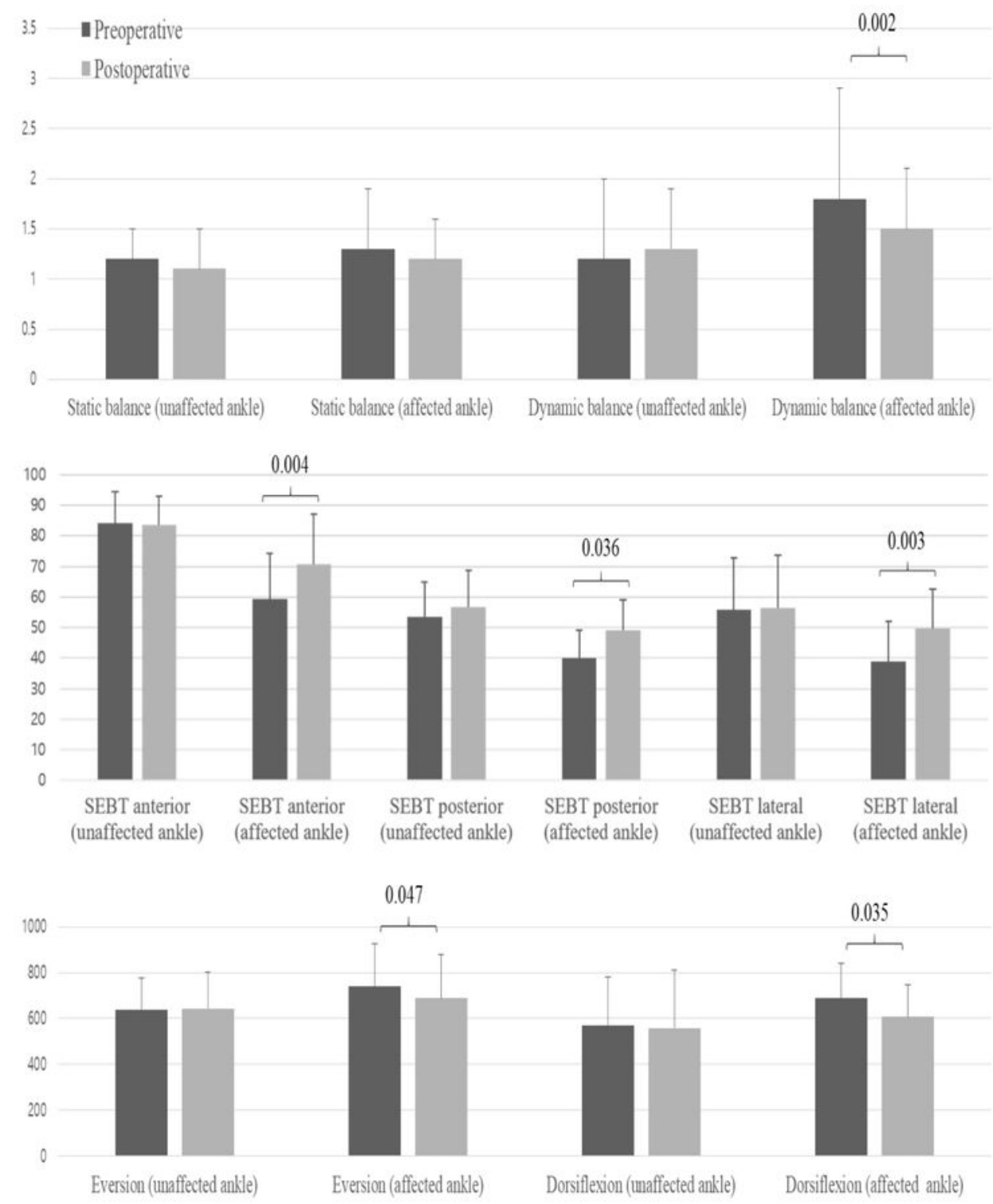

Figure 2

Postural stability, SEBT, and time to peak torque in the affected and unaffected ankles between preoperative and postoperative in the MBP group ( $\left.{ }^{*} p<0.05\right)$. SEBT: star excursion balance test, MBP: modified Broström procedure. 